\title{
Psychometric properties of the Social Cognitive Theory questionnaire for physical activity in a sample of Iranian adolescent girl students
}

\author{
M.S. Ardestani, ${ }^{1}$ S. Niknami, ${ }^{1}$ A. Hidarnia ${ }^{1}$ E. Hajizadeh ${ }^{2}$
}

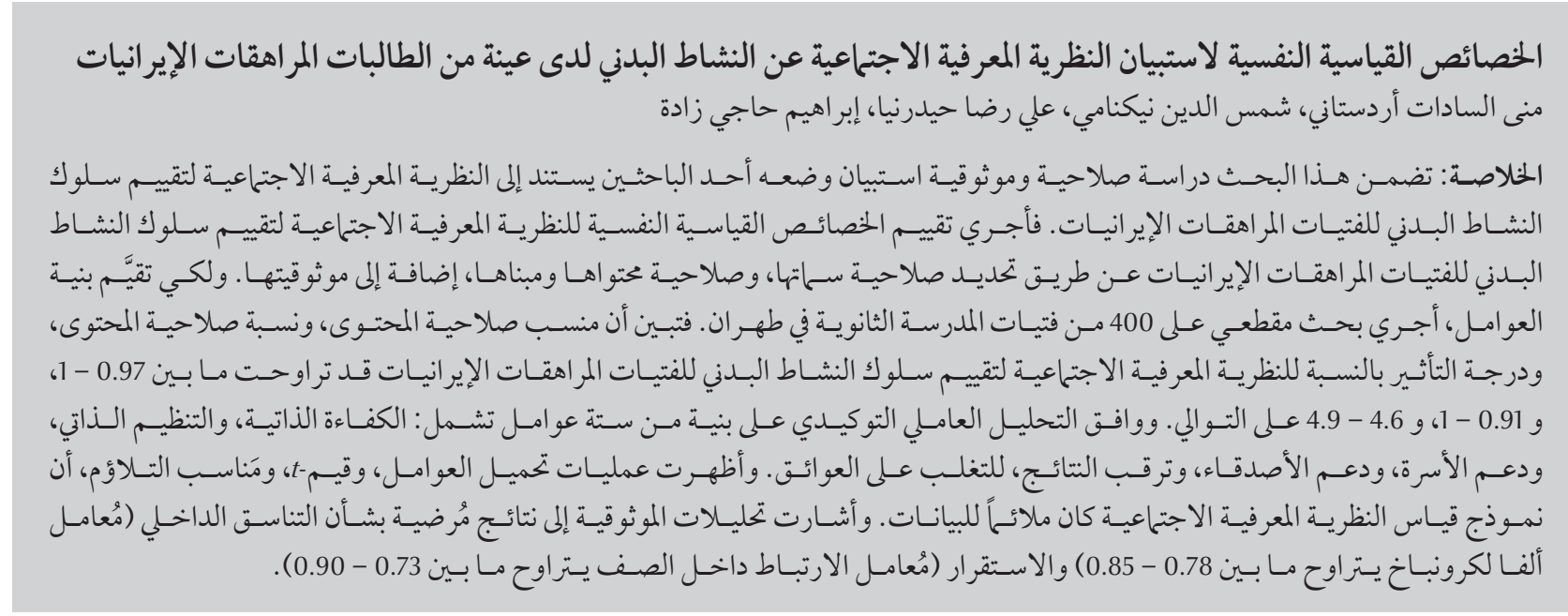

ABSTRACT This research examined the validity and reliability of a researcher-developed questionnaire based on Social Cognitive Theory (SCT) to assess the physical activity behaviour of Iranian adolescent girls (SCT-PAIAGS). Psychometric properties of the SCT-PAIAGS were assessed by determining its face validity, content and construct validity as well as its reliability. In order to evaluate factor structure, cross-sectional research was conducted on 400 high-school girls in Tehran. Content validity index, content validity ratio and impact score for the SCT-PAIAGS varied between 0.97-1, 0.91-1 and 4.6-4.9 respectively. Confirmatory factor analysis approved a six-factor structure comprising self-efficacy, self-regulation, family support, friend support, outcome expectancy and self-efficacy to overcoming impediments. Factor loadings, $t$-values and fit indices showed that the SCT model was fitted to the data. Cronbach's $\alpha$-coefficient ranged from 0.78 to 0.85 and intraclass correlation coefficient from 0.73 to 0.90 .

Propriétés psychométriques du questionnaire de théorie sociale cognitive (TSC) pour l'activité physique dans un échantillon de jeunes élèves filles iraniennes

RÉSUMÉ La présente étude visait à examiner la validité et la fiabilité d'un questionnaire mis au point par des chercheurs, basé sur la TSC, et visant à évaluer le comportement de jeunes adolescentes iraniennes en matière d'activité physique. Les propriétés psychométriques du questionnaire de TSC pour l'activité physique dans un échantillon de jeunes élèves filles iraniennes ont été évaluées en déterminant sa validité apparente, sa validité de contenu et de construit, ainsi que sa fiabilité. Afin d'évaluer la structure factorielle du questionnaire, une étude transversale a été conduite auprès de 400 lycéennes à Téhéran. L'index et le radio de validité de contenu, ainsi que le score d'impact du questionnaire de TSC pour l'activité physique dans un échantillon de jeunes élèves filles iraniennes, variaient de 0,97 à 1, de 0,91 à 1 et de 4,6 à 4,9 respectivement. L'analyse factorielle confirmatoire a validé une structure factorielle comprenant 6 aspects : I'auto-efficacité, l'auto-régulation, le soutien familial, le soutien social, l'attente du résultat et l'auto-efficacité pour dépasser les obstacles. La saturation factorielle, les valeurs de t et les indices d'ajustement ont montré que le modèle d'évaluation de la TSC était adapté aux données. Le coefficient $\alpha$ de Cronbach était compris entre 0,78 et 0,85 et le coefficient de corrélation intraclasse entre 0,73 et 0,90 .

${ }^{7}$ Department of Health Education, Faculty of Medical Sciences, Tarbiat Modares University, Tehran, Islamic Republic of Iran (Correspondence to S. Niknami: niknamis@modares.ac.ir). ${ }^{2}$ Department of Biostatistics, Faculty of Medical Sciences, Tarbiat Modares University, Tehran, Islamic Republic of Iran.

Received: 15/03/15; accepted: 17/03/16 


\section{Introduction}

Recently, the decline in physical activity level of female teenagers and its consequent health problems has been a crucial international concern (1). The decline in physical activity level is greatest during the secondary-school years (12-18 years), and previously published research consistently reports lower physical activity among adolescent girls than among adolescent boys $(1,2)$. Globally, about $80 \%$ of adolescents (aged 13-15 years) do not meet physical activity recommendations, which are at least 60 minutes of moderate to vigorous physical activity every day (1).

Prevalence of insufficient physical activity was highest in the WHO Region of the Americas and the Eastern Mediterranean Region. In both of these regions, almost $50 \%$ of women were insufficiently active, while the prevalence for men was 40\% in the Americas and $36 \%$ in the Eastern Mediterranean. In all WHO regions, men were more active than women, and the biggest difference in prevalence between the two sexes was reported in the Eastern Mediterranean Region (3).

In the Islamic Republic of Iran, the prevalence of insufficient physical activity in females and males aged 15 years and older was estimated as $46.5 \%$ and $25.2 \%$ respectively (3). In the Islamic Republic of Iran, of females between 15 and 24 years, $69.5 \%$ did no physical activity in their leisure time and $20.5 \%, 6.0 \%, 3.7 \%$ had low, moderate, and vigorous physical activity levels respectively (4). According to surveys in the 10th educational district of Tehran, $34.2 \%$ women aged 15 years and older were overweight and $14.9 \%$ were obese based on body-mass index (5). In urban areas of Islamic Republic of Iran, the level of physical activity of 15-24 year old women was low, moderate and high in $51.66 \%, 33.38 \%$ and $14.96 \%$ respectively (6). The average physical activity per day in this group was 53.07 minutes but in the same age group men did 128.2 minutes daily. In Tehran, the prevalence of low physical activity in 15-24 years women was $41 \%$ (6).

Given the complexity of physical activity behaviour, it is necessary to use behaviour change theories to identify the main factors influencing behaviour as well as any possible relationship between the main factors in physical activity and recognize key elements in order to design effective interventions (7). Social Cognitive Theory is a successful theory for understanding the framework of physical activity behaviour $(8-10)$. Social Cognitive Theory is based on a multidimensional model that represents human behaviour as dynamic and includes intrapersonal/ interpersonal characteristics, behaviour and environmental factors. The overlying mechanism in Social Cognitive Theory is reciprocal determinism $(11,12)$. Reciprocal determinism recognizes that elements of the person and the environment interact in ways that may help to shape future motivations, behaviour and well-being (13).

Accordingly, increased attention has been recently directed towards the development and evaluation of physical activity interventions targeting young people particularly in adolescent girls (14-16). Key settings for physical activity promotion among adolescents are schools, home, community and primary health care centres. Among them, the most commonly targeted setting for this age group is schools $(14,17)$, and there is strong evidence for schoolbased physical activity interventions $(14,16,17)$.

Thus, it is essential to apply validated and standard theory-based questionnaires for designing health education programmes in this setting. To our best knowledge, no study has assessed the psychometric properties of the Social Cognitive Theory scale for measuring physical activity behaviour in female adolescent students in Islamic Republic of Iran. Such a valid and reliable questionnaire can assist in conducting some Social Cognitive Theory-based research on exercise behaviour of female adolescents. Hence, the aim of this research was to test the validity and reliability of the Social Cognitive Theory questionnaire for assessing physical activity in Iranian female adolescent students (SCT-PAIAGS).

\section{Methods}

\section{The questionnaire}

An item pool was extracted from the Social Cognitive Theory literature (18-22). Banville and colleagues' method (23) was applied to crossculturally translate the SCT-PAIAGS. Two independent bilingual health researchers translated the original scale to Persian. Blind to the original questionnaire, another two bilingual health researchers back-translated the Persian form to English. Finally, an expert team comprising the translators and researchers reviewed all of the translation and cultural adaptation processes. Agreement in terms of semantic, idiomatic and conceptual equivalence was reached, and a final version of the scale was provided (24).

The SCT-PAIAGS contained six constructs: self-efficacy, self-regulation, family support, friend support, outcome expectancy and self-efficacy to overcoming impediments.

There has been research looking at these constructs to study physical activity behaviour in different groups. The findings of this assessment showed successful prediction of physical activity behaviour by this structure (24-26) We assessed these constructs in a group of female students in Tehran, Islamic Republic of Iran. This group was chosen randomly from a district in Tehran and represented a common intermediate socioeconomic level of Tehrani adolescent girls. They were $15-16$ years old. The characteristics of this group are 


\begin{tabular}{|c|c|}
\hline \multicolumn{2}{|c|}{$\begin{array}{l}\text { Table } 1 \text { Demographic characteristics and physical activity rate/level of the } \\
\text { participants }(n=400)\end{array}$} \\
\hline Variable & Value \\
\hline & Mean (SD) \\
\hline Age (years) & $15.52(0.50)$ \\
\hline Father's occupation & No. (\%) \\
\hline Worker & $43(10.8)$ \\
\hline Employee & $120(30.0)$ \\
\hline Self-employed & $197(49.2)$ \\
\hline Retired & $31(7.8)$ \\
\hline Unemployed & $9(2.2)$ \\
\hline \multicolumn{2}{|l|}{ Mother's occupation } \\
\hline Worker & $5(1.2)$ \\
\hline Employee & $41(10.2)$ \\
\hline Self-employed & $17(4.2)$ \\
\hline Retired & $2(0.5)$ \\
\hline Housekeeper & 335 (83.8) \\
\hline \multicolumn{2}{|l|}{ Father's education } \\
\hline Illiterate & 49 (12.2) \\
\hline Low literate & $305(76.2)$ \\
\hline Diploma & $28(7.0)$ \\
\hline Bachelor & $18(4.5)$ \\
\hline \multicolumn{2}{|l|}{ Mother's education } \\
\hline Illiterate & $59(14.8)$ \\
\hline Low literate & $302(75.6)$ \\
\hline Diploma & $23(5.8)$ \\
\hline Bachelor & $16(4.0)$ \\
\hline Physical activity & Mean (SD) \\
\hline \multirow[t]{2}{*}{ Minutes per week } & $53.12(13.92)$ \\
\hline & No. $(\%)$ \\
\hline Inactive (0 minutes per week) & $0(0)$ \\
\hline Less active (< 420 minutes per week) & $400(100)$ \\
\hline Active ( $\geq 420$ minutes per week) & $0(0)$ \\
\hline
\end{tabular}

$S D=$ standard deviation

noted in Table 1. Both inclusion and exclusion criteria are listed later.

Self-efficacy scale was a 10-item construct that measured the confidence of the participants in doing exercise. The response range was $0 \%$ to $100 \%$ (from could not exercise to could exercise). Self-efficacy was defined as confidence, personal competence and belief in the ability to perform the given behaviour. Assessment of self-efficacy was done in a similar way to other scales. The response range was from 1 to 5 (25).
The self-regulation construct contained nine items. Students responded to each item on a five-point Likert scale ( $1=$ not at all; $5=$ completely). Selfregulation was a constant influence on health behaviour change as an integral part of an individual's ability to exert control over her external and internal environment (26).

Family and friends support structures assessed participant's perception of their social support for exercise. A five-point Likert format was used to measure each statement $(1=$ none, $5=$ very often). Social situation referred to a person's perception of her own social environment. Social support included family and/or friends' support. Many people find it easier to change a behaviour if those around them provide support or are willing to be partners in the behaviour change process. This can work as an incentive for behaviour change (25).

Outcome expectancy construct indicated the participant's level of agreement with positive and negative statements regarding the possible effects of regular exercise $(1=$ not at all likely; 5 = extremely likely). Participants showed the value of each outcome, by rating the personal importance of each of the statements, ranging from $1=$ not at all important to $5=$ extremely important. Outcome expectation was the anticipated aspect of behaviour that was categorized to include detrimental or beneficial physical effects, positive and negative social consequences and internalized self-incentives. Outcome expectancy was the value a person placed on a particular outcome (25).

Self-efficacy to overcoming impediments consisted of four items with a Likert-scale response format $(1=$ not at all sure, $4=$ totally sure). This construct was defined as the confidence that students had in overcoming barriers while performing a given behaviour (27). This construct is related to self-efficacy in terms of being situation-specific, pertaining to the present and being a confidence level. Sometimes it is considered as a subset of self-efficacy, but is better to consider it as a separate construct (11).

\section{Content and face validity}

An expert panel comprising 10 health and physical education specialists evaluated the grammar, wording, item allocation and scaling of the SCT-PAIAGS in a qualitative manner. In the quantitative method, the content validity index (CVI) and the content validity ratio (CVR) were calculated. CVI assessed the relevance, simplicity and clarity of 
an item to the content represented in the research questionnaire. For calculating the CVI, a Likert-type ordinal scale with four possible responses was used: $1=$ not relevant, not simple and not clear to $4=$ very relevant, very simple and very clear. CVI was estimated as the proportion of items that received a rating of 3 or 4 by the experts (28). Polit and Beck recommended 0.8 for the acceptable lower limit for CVI value (29). CVR examined the necessity of an item's being in the questionnaire (30). For calculating this index the experts rated each item as essential, useful but not essential, or not essential (28). Face validity was determined by both qualitative and quantitative methods: In the qualitative stage, 20 female students of the target group were asked to assess the scale and indicate if they felt that there was difficulty, irrelevancy or ambiguity in responding to the questionnaire or not. Those students were excluded from participating in subsequent stages. The impact score (frequency $\times$ importance) was used to indicate the percentage of girls who identified that an item was important or quite important (quantitative method). Those items associated with an impact score equal or greater than 1.5 were considered appropriate (28).

\section{Construct validity}

Confirmatory factor analysis (CFA) was used to assess construct validity and test the assumed theoretical framework behind the instrument. Participants $(n=$ 400) were randomly selected with multistage sampling. Calculation of sample size was based on 5 to 10 students per item of each construct (27). The total sample size was 1000 .

In this method, we randomly selected an educational district in Tehran. Then a number of schools were randomly chosen from the list of the schools in that chosen district. In all, 400 students participated in this study.

Inclusion criteria were: being a 15-16 year old female student, being interested in engaging in this research, lack of disability and not attending other physical activity programmes; and exclusion criteria included having medical contraindications for exercise and students' or their parents' disagreeing to participate in this study. Data were collected by health education researchers.

\section{Reliability}

The internal consistency of the SCTPAIAGS was checked using Cronbach's $\alpha$-coefficient. $\alpha$ values of 0.70 or above were considered satisfactory (31). We evaluated the stability (test-retest reliability) of the SCT-PAIAGS by intraclass correlation coefficient (ICC). Female students $(n=30)$ completed the questionnaires twice, with a 2-week interval. Those girls were omitted from participating in later stages of the research. An ICC of $<0.40$ was considered poor to fair, $0.41-0.60$ moderate, $0.61-0.80$ good and $>0.80$ excellent agreement (32).

\section{Physical activity measure}

In this study, target physical activity behaviour for students was selected according to WHO recommendations. According to WHO recommendations, children and young people between 5 and 17 should have at least 60 minutes of physical activity of moderate (e.g. hiking, skateboarding, rollerblading, bicycle riding) to vigorous (e.g. running and chasing, such as tag, skipping, running) intensity every day.

We measured physical activity via the short form of the International Physical Activity Questionnaire (IPAQ). The IPAQ has become the most widely used physical activity questionnaire. The short form records physical activity in four intensity levels: vigorousintensity activity; moderate-intensity activity; walking; and sitting (33). There are also three levels of physical activity: low, moderate and high (33).

\section{Statistical analysis}

Data were analysed with SPSS 16 and LISREL 8.8 applying Cronbach's $\alpha$, intraclass correlation coefficient, maximum likelihood estimation and covariance matrix. We assessed the fitness of the Social Cognitive Theory model applying many fitness indices: chi-squared $\left(\chi^{2}\right)$ should be nonsignificant to indicate a good fit (34), $\chi^{2} /$ degrees of freedom $<3$ (35), root mean square error of approximation (RMSEA) $\leq 0.06$, root mean square residual (RMSR) $\leq 0.08$ (34) goodness of fit index (GFI) (35), adjusted goodness of fit index (AGFI) $\geq$ 0.80 (36), showing a good fit.

\section{Ethical issues}

This study was approved by the ethics committee of Tarbiat Modares University. All participants gave their permission by signing an informed consent form. The subjects were told about the general nature of the research and were assured of the confidentiality of the data.

\section{Results}

The findings of qualitative content validity were appropriate, regarding to grammar, wording, item allocation and scaling. The CVI and CVR for the total items were $0.97-1$ and $0.91-1$, indicating a satisfactory result in the quantitative phase. In assessing qualitative face validity, all participants acknowledged that they had no problems in reading and understanding the items. Quantitative face validity showed that the range of impact score was 4.6-4.9.

A total of 400 completed questionnaires was used in the path analysis study. Generally, most parents of students were poorly literate. All students had insufficient physical activity. Students' demographic characteristics and their physical activity rate/level are shown in Table 1.

Confirmatory factor analysis confirmed the six-factor structure (selfefficacy, self-regulation, family support, 
friend support, outcome expectancy and self-efficacy) for overcoming impediments. Standard solution (factor loading) related to each item is presented in Figure 1. All $t$-values were significant $(P<0.05)$, indicating the significance level of the factor loadings. Coefficients of determination $\left(R^{2}\right)$ showed variance of an item, which was explained by respective latent variable. $R^{2}$ implies explained variance by each factor (construct) (Table 2). Fitness indices showed that the Social Cognitive Theory model fitted the data of this study (Table 3).

The mean of Cronbach's a for the subscales of SCT-PAIAGS was 0.81 (range: $0.78-0.85$ ) (Table 4). The ICC for this questionnaire's subscales was good to excellent (ICC ranged from 0.73 to 0.90 ) (Table 4 ).

\section{Discussion}

This study was the first to describe psychometric properties of the SCTPAIAGS. In all, our findings confirmed the validity and reliability of the SCTPAIAGS. According to the expert panel, content validity of the scale was satisfactory. Determining face validity of the scale, participants declared that the scale was clearly addressing important issues related to physical activity. Hence, as a valid and reliable instrument, it will help designing and evaluating theorybased health education interventions (37). The findings of this study demonstrated that adolescent female students who participated in this study

Figure 1 The results obtained from the confirmatory factor analysis. SEO: Selfefficacy to overcome barriers, FA: family support, FI: friend support, SR: self regulation, E: outcome expectancies, and S: self-efficacy.One-sided short arrows: Errors of the model, One-sided long arrows: Factor loadings, Two-sided arrows: Covariance between latent factors, seo1..... s10: Items of the Social Cognitive Theory questionnaire or observed variables

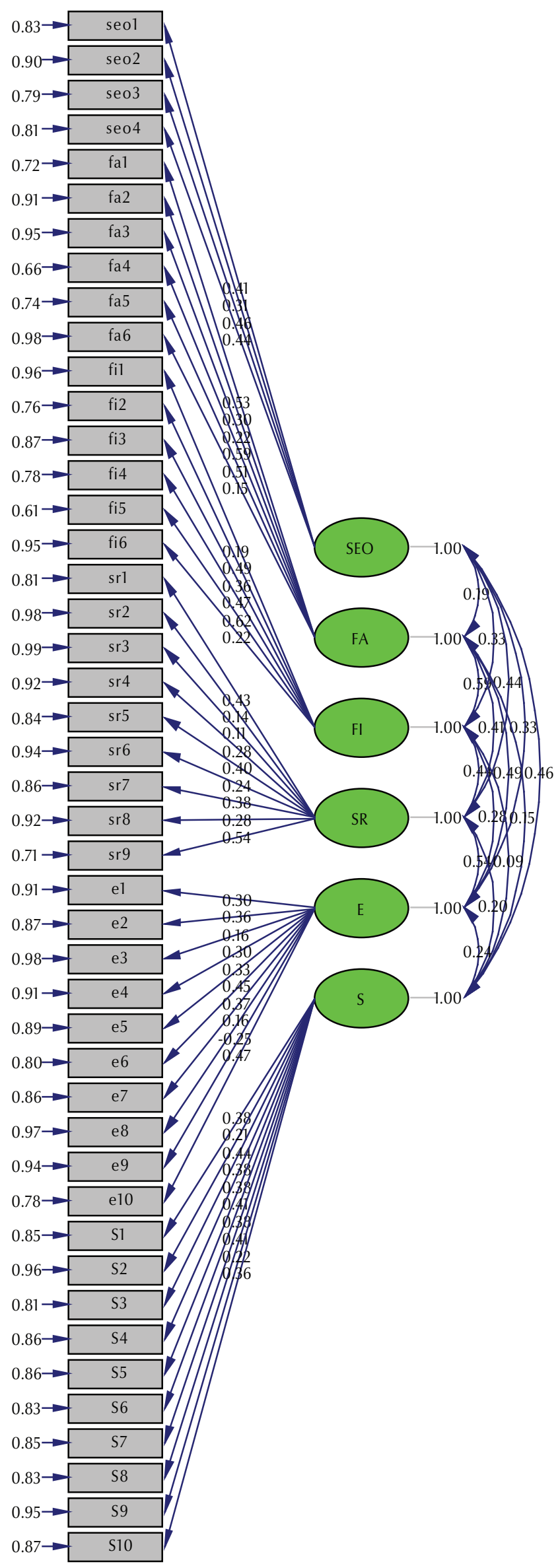




\begin{tabular}{|c|c|c|}
\hline $\begin{array}{l}\text { Latent variables } \\
\text { (constructs) }\end{array}$ & Observed variables (items) & $R^{2}$ \\
\hline \multirow[t]{10}{*}{ Self-efficacy } & I could exercise during or following a personal crisis & 0.15 \\
\hline & I could exercise when feeling depressed & 0.04 \\
\hline & I could exercise when feeling anxious & 0.19 \\
\hline & I could exercise during bad weather & 0.14 \\
\hline & I could exercise when on vacation & 0.14 \\
\hline & I could exercise when there are competing interests (e.g. watching television) & 0.17 \\
\hline & I could exercise when I have a lot of work to do & 0.15 \\
\hline & I could exercise when I didn't receive support from my family/friends & 0.17 \\
\hline & I could exercise when exercising is not enjoyable & 0.04 \\
\hline & I could exercise when I hadn't reached my exercise goals & 0.13 \\
\hline \multirow[t]{9}{*}{ Self-regulation } & I often set exercise goals & 0.19 \\
\hline & My exercise goals help to increase my motivation for doing exercise & 0.02 \\
\hline & I tend to break more difficult exercise goals down into a series of smaller goals & 0.01 \\
\hline & I usually keep track of my progress in meeting my goals & 0.08 \\
\hline & If I do not reach an exercise goal, I analyse what went wrong & 0.16 \\
\hline & Exercise is generally a high priority when I plan my schedule & 0.06 \\
\hline & I schedule my exercise at specific times each week & 0.14 \\
\hline & I write my planned activity sessions in an appointment book or calendar & 0.08 \\
\hline & I seem to have enough time to exercise & 0.29 \\
\hline \multirow[t]{6}{*}{ Family support } & Exercised with me & 0.28 \\
\hline & Gave me encouragement to stick with my exercise programme & 0.09 \\
\hline & Planned to exercise on recreational outings & 0.04 \\
\hline & Talked about how much they like to exercise & 0.34 \\
\hline & Helped plan activities around my exercise & 0.26 \\
\hline & Made positive comments about my physical appearance & 0.02 \\
\hline \multirow[t]{6}{*}{ Friend support } & Exercised with me & 0.03 \\
\hline & Gave me encouragement to stick with my exercise programme & 0.24 \\
\hline & Planned to exercise on recreational outings & 0.13 \\
\hline & Talked about how much they like to exercise & 0.22 \\
\hline & Helped plan activities around my exercise & 0.39 \\
\hline & Made positive comments about my physical appearance & 0.04 \\
\hline \multirow[t]{10}{*}{ Outcome expectancy } & I will feel less depressed and/or bored & 0.09 \\
\hline & I will improve my self-esteem & 0.13 \\
\hline & It will make me feel tired & 0.02 \\
\hline & Will feel less tension and stress & 0.09 \\
\hline & I will improve my health or reduce my risk of disease & 0.11 \\
\hline & I will do better on my job & 0.20 \\
\hline & I will feel more attractive & 0.14 \\
\hline & I will improve my heart and lung fitness & 0.02 \\
\hline & It will cost too much money & 0.06 \\
\hline & I will increase my energy level & 0.22 \\
\hline \multirow{4}{*}{$\begin{array}{l}\text { Self-efficacy to } \\
\text { overcoming } \\
\text { impediments }\end{array}$} & Get up early, even on weekends, to exercise & 0.17 \\
\hline & Stick to your exercise programme after a long tiring day of school/work & 0.09 \\
\hline & Attend a social event/party only after exercising & 0.21 \\
\hline & $\begin{array}{l}\text { Stick to your exercise programme even when you have excessive demands at } \\
\text { school or work }\end{array}$ & 0.19 \\
\hline
\end{tabular}




\begin{tabular}{|c|c|c|c|c|c|c|c|}
\hline $\begin{array}{l}\text { Fit index } \\
\text { Model }\end{array}$ & $x^{2 *}$ & df & $x^{2} / \mathrm{df}$ & GFI & AGFI & RMSEA & RMR \\
\hline Social Cognitive Theory & 2065.96 & 930 & 2.22 & 0.84 & 0.83 & 0.04 & 0.02 \\
\hline
\end{tabular}

*P $<0.05$.

$G F I=$ goodness offit index $; A G F=$ adjusted goodness of fit index; $R M S E A=$ root mean square error of approximation; $R M R=$ root mean square residual .

were not adequately active. Similar findings have been shown in other studies too $(38,39)$. Therefore, it is necessary to assess the physical activity behaviour of female adolescents by valid and reliable instruments and design interventions based on the assessment results. The reliability analysis of the SCT-PAIAGS was also satisfactory. Consistent with our findings, Pirasteh and colleagues' study indicated satisfactory Cronbach's a, mean inter-item correlations and test-retest coefficients (38). Similarly, Cronbach's $\alpha$-coefficient in Haider's study was above 0.80 for all subscales, and internal consistency proved good to excellent (27).

Moreover, confirmatory factor analysis verified construct validity of the SCT-PAIAGS, with the constructs of self-efficacy, self-regulation, family support, friend support, outcome expectancy, and self-efficacy to overcoming impediments. In Pirasteh and associates' research on adolescent girls, self-efficacy scale contained a single factor, and the scale of social support contained two factors: family support and friend support (38). Dishman and colleagues also reported supporting the factorial validity of the scales in all groups in their study
(40). In Ramirez and associates' study, confirmatory factor analyses based on Social Cognitive Theory indicated an adequate fit of the specified model about the physical activity behaviour in children with mean age $=9.8$ years. Their fit model included self-efficacy, outcome expectations, social support, barriers and goals. Furthermore, their study supported the use of Social Cognitive Theory constructs in understanding physical activity behaviour (41). Rovniak and colleagues used Social Cognitive Theory to describe university students' physical activity and demonstrated a good fit of the Social Cognitive model to the data (26). In Petosa's study, a model with the constructs of self-regulation, outcome expectancy, and social support had a good fit to data (42). In Lubans and colleagues' study, which aimed to assess physical activity in adolescent girls, using Social Cognitive Theory, a model with the constructs of self-efficacy, selfregulation and social support had a good fit to the data (15). The results of Wolfe's dissertation showed that intervention based on the constructs of Social Cognitive Theory was successful in increasing the short- and long-term exercise rates of the participants. Self-regulation was

\begin{tabular}{lcc}
\hline $\begin{array}{l}\text { Table 4 Reliability of the SCT-PAIAGS constructs } \\
\text { Construct }\end{array}$ & $\begin{array}{c}\text { Cronbach } \boldsymbol{\alpha} \\
\text { Intraclass correlation } \\
\text { coefficient }\end{array}$ \\
Self-efficacy & 0.85 & 0.90 \\
Self-regulation & 0.81 & 0.75 \\
Family support & 0.79 & 0.80 \\
Friend support & 0.83 & 0.73 \\
Outcome expectancy & 0.78 & 0.80 \\
Self-efficacy to overcoming & 0.80 & 0.81 \\
impediments & 0.81 & 0.79 \\
Total & & \\
\hline
\end{tabular}

important in her study. Although the mean score of self-efficacy was increased in the intervention group, the difference in the mean score of self-efficacy between intervention and control groups was not significant. In another study, social support and outcome expectancies appeared to have the least successful impacts in the interventions for exercise adherence (25). Haider in his dissertation assessed the role of self-efficacy, social support, outcome expectancies and self-efficacy to overcome barriers in predicting the exercise behaviour of college students in south Asia and found that only self-efficacy was a predictor of students' exercise behaviour (27). The findings from Soleymanian and associates' study showed that the data obtained from assessing physical activity behaviour of female adults fitted with the constructs of the Health Beliefs Model combined with the construct of selfregulation (43).

In conclusion, the six constructs of Social Cognitive Theory (self-efficacy, family support, friend support, outcome expectancy, self-regulation, self-efficacy to overcoming impediments) can predict the exercise behaviour of female adolescents.

There are some limitations to the study. Students' physical activity was measured through self-reported scales, which may affect the study findings because of participant overestimation or underestimation. Generalization of the findings of this study on Tehrani female adolescents to the entire Iranian female adolescent students was not appropriate. Therefore, the results of this study have to be interpreted with some caution. Further studies are needed based on larger samples. 


\section{Conclusion}

The present study demonstrated the content, face and construct validity and reliability of the SCT-PAIAGS. This will help conduct Social Cognitive Theorydriven research about physical activity behaviour in female adolescent students.
Acknowledgements

This study originated from the first author's (Mona Sadat Ardestani) doctoral thesis at the Faculty of Medical Sciences, Tarbiat Modares University, Tehran, Islamic Republic of Iran.
The authors are grateful to all the participants who helped us, especially the teachers in the schools under research, Saeideh Ghaffarifar and Zeinab Gholamnia Shirvani.

Funding: This research was funded by Tarbiat Modares University.

Competing interests: None declared.

\section{References}

1. Hallal PC, Andersen LB, Bull FC, Guthold R, Haskell W, Ekelund U. Global physical activity levels: surveillance progress, pitfalls, and prospects. Lancet. 2012;380(9838):247-57.

2. Olds T, Dollman J, Maher C. Adolescent sport in Australia: Who, when, where and what. ACHPER Healthy Lifestyles Journal. 2009;56(1):11-6.

3. Global status report on noncommunicable diseases 2010. Geneva: World Health Organization; 2011.

4. Delavari A, Alikhani S, Alaeddini F. Report of risk factor of noncommunicable diseases in the Islamic Republic of Iran., Tehran: Ministry of Health and Medical Education, Seda Press; 2004.

5. Vaez Mahdavi MR, Asadi Lari M. [Urban health Tehran experience, Round 2 Results. 1st ed]. Tehran: Municipality of Tehran; 2013 [in Farsi].

6. Asgari F, Rafei A, Azimi S, Rezanejad-Asl P, Heidarian-Miri H. I.R. Iran Non-Communicable Diseases Risk Factors Surveillance. Provincial report 2009 (http://www.ncdinfobase.ir/docs.asp, accessed 1 May 2015)

7. Nutbeam D, Harris E, Wise W. Theory in a nutshell: a practical guide to health promotion theories. Sydney, Australia: McGraw-Hill; 2010.

8. Culp RH. Adolescent girls and outdoor recreation: a case study examining constraints and effective programming. J Leis Res. 1998;30(3):356-79

9. Allen N. Social cognitive theory in diabetes exercise research: an integrative literature review. Diabetes Educ. 2004;30(5):805-19.

10. Bandura A. Health promotion from the perspective of social cognitive theory. Psychol Health. 1998;13(4):623-49.

11. Sharma M, Romas JA. Theoretical foundations of health education and health promotion. 2nd ed. Sudbury (Massachusetts): Jones and Bartlett Publishers; 2011

12. Glanz K, Rimer BK, Viswanath K. Health behavior and health education: theory, research, and practice. Chichester, John Wiley \& Sons; 2008

13. Bandura A. Health promotion by social cognitive means. Health Educ Behav. 2004;31(2):143-64.

14. Camacho-Miñano MJ, LaVoi NM, Barr-Anderson DJ. Interventions to promote physical activity among young and adolescent girls: a systematic review. Health Educ Res. 2011;26(6):1025-49.

15. Lubans DR, Okely AD, Morgan PJ, Cotton W, Puglisi L, Miller J. Description and evaluation of a social cognitive model of physical activity behaviour tailored for adolescent girls. Health Educ Res. 2012;27(1):115-28.

16. Webber LS, Catellier DJ, Lytle LA, Murray DM, Pratt CA, Young DR, et al. Promoting physical activity in middle school girls: trial of activity for adolescent girls. Am J Prev Med. 2008;34(3):17384.

17. Demetriou $Y$, Höner O. Physical activity interventions in the school setting: a systematic review. Psychol Sport Exerc. 2012;13(2):186-96.
18. Anderson ES, Wojcik JR, Winett RA, Williams DM. Socialcognitive determinants of physical activity: the influence of social support, self-efficacy, outcome expectations, and self-regulation among participants in a church-based health promotion study. Health Psychol. 2006;25(4):510.

19. Williams DM, Anderson ES, Winett RA. A review of the outcome expectancy construct in physical activity research. Ann Behav Med. 2005;29(1):70-9.

20. Wallace L, Buckworth J, Kirby T, Sherman W. Characteristics of exercise behavior among college students: application of social cognitive theory to predicting stage of change. Prev Med. 2000;31(5):494-505.

21. Peterson J. Get moving! Physical activity counseling in primary care. J Am Acad Nurse Pract. 2007;19(7):349-57.

22. Ghaffarifar S, Ghofranipour F, Ahmadi F, Khoshbaten M, Sallis $C$. The causal relationship between interns' knowledge and self-efficacy and their value in predicting the interns' communication behavior with patients. Int J Community Based Nurs Midwifery. 2015;3(4):263.

23. Banville D, Desrosiers P, Genet-Volet Y. Translating questionnaires and inventories using a cross-cultural translation technique. J Teach Phys Educ. 2000;19(3):374-87.

24. Bazarganipour F, Ziaei S, Montazeri A, Faghihzadeh S, Frozanfard F. Psychometric properties of the Iranian version of modified polycystic ovary syndrome health-related qualityof-life questionnaire. Hum Reprod. 2012;27(9):2729-36.

25. Wolfe ME. An evaluation of an exercise adherence intervention using the Social Cognitive Theory [PhD thesis]. Columbus: Ohio State University; 2008.

26. Rovniak LS, Anderson ES, Winett RA, Stephens RS. Social cognitive determinants of physical activity in young adults: a prospective structural equation analysis. Ann Behav Med. 2002;24(2):149-56.

27. Haider T. Using Social Cognitive Theory to predict exercise behavior among college students of south Asian descent at two large midwestern universities [MPH thesis]. Cincinnati: University of Cincinnati; 2011.

28. Hajizadeh E, Asghari M. [Statistical methods and analyses in health and biosciences. a research methodological approach using SPSS practical guide. 1st ed]. Tehran: Publications of the Academic Jihad Organization; 2011 [in Farsi].

29. Polit DF, Beck CT. Nursing research: principles and methods. 7th ed. Philadelphia: Lippincott Williams \& Wilkins; 2004.

30. Lawshe $\mathrm{CH}$. A quantitative approach to content validity. Personnel psychology (PERS PSYCHOL). 1975; 28(4): 563-75.

31. Cronbach LJ. Coefficient alpha and the internal structure of tests. Psychometrika. 1951;16(3):297-334.

32. Bartko JJ. The intraclass correlation coefficient as a measure of reliability. Psychological reports. Psychol Rep. 1966;19(1):3-11. 
33. International Physical Activity Questionnaire (Iphysical activityQ). Guidelines for Data Processing and Analysis of the International Physical Activity Questionnaire (Iphysical activityQ)-Short and Long Forms November 2005 (https://www.

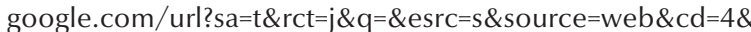
cad=rja\&uact $=8 \&$ ved $=0$ ahUKEwiTw_qeoKLNAhXMORoKHe KLDi0QFgg2MAM\&url=https\%3A\%2F\%2Fwww.researchgate. net\%2Ffile.PostFileLoader.html\%3Fid\%3D56f92d66615e27d 49a658031\%26assetKey\%3DAS\%253A344600888791041\%25 401459170662924\&usg=AFQjCNFu86dTe_OuPWO-puYIPh GnZbyAhw\&bvm=bv.124272578,d.d2s; accessed 1 May 2016.

34. Hu Lt, Bentler PM. Cutoff criteria for fit indexes in covariance structure analysis: conventional criteria versus new alternatives. Struct Equ Modeling. 1999;6(1):1-55.

35. Munro B. Statistical methods for health care research. Philadelphia: Lippincott Williams \& Wilkins; 2005.

36. Kalantari K. Structural equation modelling in social and economical sciences. Tehran: Saba Publishing; 2009.

37. Blue CL, Marrero DG. Psychometric properties of the healthful eating belief scales for persons at risk of diabetes. J Nutr Educ Behav. 2006;38(3):134-42.

38. Pirasteh A, Hidarnia A, Asghari A, Faghihzadeh S, Ghofranipour F. Development and validation of psychosocial determinants measures of physical activity among Iranian adolescent girls. BMC Public Health. 2008;8(1):150.

39. Taimoori P, Niknami Sh, Berry T, Ghofranipour F, Kazemnejad A. Application of the health promotion model to predict stages of exercise behaviour in Iranian adolescents. East Mediterr Health J. 2009;15(5):1215-26.

40. Dishman RK, Hales DP, Sallis JF, Saunders R, Dunn AL, Bedimo-Rung AL, et al. Validity of social-cognitive measures for physical activity in middle-school girls. J Pediatr Psychol. 2009; 35(1):72-88.

41. Ramirez E, Kulinna PH, Cothran D. Constructs of physical activity behaviour in children: the usefulness of Social Cognitive Theory. Psychol Sport Exerc. 2012;13(3):303-10.

42. Petosa RL, Suminski R, Hortz B. Predicting vigorous physical activity using social cognitive theory. Am J Health Behav. 2003;27(4):301-10.

43. Soleymanian A, Niknami SH, Hajizadeh E, Shojaeizadeh D, Montazeri A. Development and validation of a health belief model based instrument for measuring factors influencing exercise behaviors to prevent osteoporosis in pre-menopausal women (HOPE). BMC Musculoskelet Disord. 2014;15:61. 